\title{
Neuroendocrine Tumors of the Bronchopulmonary System (Typical and Atypical Carcinoid Tumors): Current Strategies in Diagnosis and Treatment. Conclusions of an Expert Meeting February 2011 in Weimar, Germany
}

\author{
Dieter Hörsch $^{a}$ Kurt W. Schmid ${ }^{b}$ Martin Anlauf ${ }^{c, d}$ Kaid Darwiche ${ }^{e}$ Tim Denecke $^{f}$ \\ Richard P. Baum ${ }^{g} \quad$ Christine Spitzweg $^{\mathrm{h}} \quad$ Christian Grohéi Norbert Presselt $^{\mathrm{k}}$ \\ Christian Stremmel $\quad$ David F. Heigener ${ }^{\mathrm{m}} \quad$ Monika Serke $^{\mathrm{n}}$ Thomas Kegel $^{\mathrm{o}}$ Marianne Pavel $^{\mathrm{p}}$ \\ Cornelius F. Waller ${ }^{q}$ Karl-Matthias Deppermann ${ }^{r}$ Rudolf Arnold ${ }^{s}$ Rudolf M. Huber ${ }^{t}$ \\ Matthias M. Weber ${ }^{\mathrm{u}}$ Hans Hoffmann ${ }^{\mathrm{v}}$
}

${ }^{a}$ Klinik für Innere Medizin, Gastroenterologie und Endokrinologie, Zentralklinik Bad Berka; ${ }^{b}$ Institut für Pathologie, Universitätsklinikum Essen; 'Institut für Pathologie und Endokrines Tumorzentrum, Heinrich-Heine-Universität Düsseldorf; 'Institut für Pathologie und Zytologie Gießen/Limburg/Wetzlar, St. Vincenz Krankenhaus Limburg; ${ }^{e}$ Abteilung Interventionelle Pneumologie, Ruhrlandklinik, Essen; ${ }^{f}$ Klinik für Strahlenheilkunde, Charité - Universitätsmedizin Berlin; ${ }^{9}$ Klinik für Molekulare Radiotherapie, Zentralklinik Bad Berka; ${ }^{\mathrm{h} Z e n-}$ trum für neuroendokrine Tumoren, Universitätsklinikum Großhadern, München; 'Klinik für Pneumologie, Evangelische Lungenklinik Berlin; ${ }^{k}$ Klinik für Thorax- und Gefäßchirurgie, Zentralklinik Bad Berka; 'Chirurgische Uniklinik, Abteilung Thoraxchirurgie, Albert-LudwigsUniversität Freiburg; ${ }^{\mathrm{m} O n k o l o g i e ~ L u n g e n C l i n i c, ~ G r o ß h a n s d o r f ; ~}{ }^{\mathrm{T}}$ Team Pneumologie, Lungenklinik, Hemer; ${ }^{\circ}$ Hämatologische/Onkologische Ambulanz, Martin-Luther-Universität Halle-Wittenberg, Halle; ${ }^{p}$ Medizinische Klinik mit Schwerpunkt Hepatologie und Gastroenterologie, Charité Berlin; 'Innere Medizin I - Onkologie, Hämatologie und Stammzelltransplantation, Medizinische Universitätsklinik, Freiburg; 'Pneumologie und Schlafmedizin, HELIOS Klinikum, Erfurt; 'München; 'Pneumologie Innenstadt und Thorakale Onkologie, Klinikum der Ludwig-Maximilians-Universität München und Lungentumorzentrum, München; "I. Medizinische Klinik und Poliklinik, Universitätsklinikum Mainz; 'Thoraxklinik am Universitätsklinikum Heidelberg, Germany

\section{Keywords}

Neuroendocrine tumors · Carcinoid tumor · Neuroendocrine carcinoma $\cdot$ Respiratory tract neoplasms

\section{Summary}

Neuroendocrine tumors (NETs; syn. carcinoid tumors) are highly or moderately differentiated neoplasms. They comprise a large variety of rare and heterogeneous tumors with an estimated incidence of 3-5/100,000/year. They can arise in virtually every internal organ, but mainly occur in the gastroenteropancreatic and bronchopulmonary systems. Around $25 \%$ of the NETs are localized in the bronchopulmonary system. Approximately $2 \%$ of all lung tumors are NETs. According to the World Health Organization (WHO) classification of lung tumors, bronchopulmonary NETs are subdivided into typical carcinoids (TCs) and atypical carcinoids (ACs). The parameter with the highest impact on NET behavior and prognosis is the histological classification and staging according to the tumor/node/metastasis (TNM) system. The diagnosis of NETs is established by histological examination and the immunohistochemical detection of general neuroendocrine markers, such as chromogranin $\mathrm{A}(\mathrm{CgA})$ and synaptophysin. Serum markers and the use of functional imaging techniques are important additive tools to establish the diagnosis of a NET. The only curative option for lung NETs is complete surgical resection. Beyond that, the currently available interdisciplinary therapeutic options are local ablation, biotherapy (somatostatin analogues), or chemotherapy. New therapeutic options such as peptide receptor radionuclide therapy (PRRT) and molecularly targeted therapies achieve promising results and are under further evaluation. This report is a consensus summary of the interdisciplinary symposium 'Neuroendocrine Tumors of the Lung and of the Gastroenteropancreatic System (GEP NET) - Expert Dialogue' held on February 25-26, 2011 in Weimar, Germany. At this conference, a panel of 23 German experts shared their knowledge and exchanged their thoughts about research, diagnosis, and clinical management of NETs, whereby special attention was paid to NETs of the respiratory tract.

\section{KARGER}

Fax +497614520714

Information@Karger.com

www.karger.com (c) 2014 S. Karger GmbH, Freiburg

2296-5270/14/0375-0266\$39.50/0

Accessible online at:

www.karger.com/ort 


\section{Introduction}

The term neuroendocrine tumor (NET) refers to a very heterogeneous group of highly or moderately differentiated tumors characterized by their capacity to accumulate and secrete peptide hormones or biogenic amines according to their cell of origin. It comprises a huge variety of possible primary tumor localizations, with the lung and different organs of the gastrointestinal (GI) tract being mostly involved. The classification of NETs is based on:

- histology

- proliferative activity

- tumor/node/metastasis (TNM) staging

- endocrine activity

- hereditary background

Exact classification of NETs is crucial for risk stratification and therapeutical management [1-5].

\section{Epidemiology, Classification, and Prognosis}

Based on overall 35,618 NET cases that have been included into the huge US American Surveillance, Epidemiology and End Results (SEER) database from 1973 to 2004, the overall incidence of NETs accounts for 3-5 per 100,000 per year, and the estimated 29-year limited-duration prevalence is 35 per 100,000 [6]. Accordingly, the number of new NET cases in Germany can be estimated within a range between 1,600 and 4,000 per year. So far, the German Registry for Gastrointestinal Neuroendocrine Tumors (Deutsches Register Neuroendokrine Gastrointestinale Tumore) has included a large series of more than 2,000 patients, but less than 50 patients with bronchopulmonary NETs. Therefore, the collection of epide- miological and clinical data on bronchopulmonary NETs in Germany is still insufficient.

The registered number of patients with lung NETs has been increasing worldwide. Different reasons for this can be suspected, such as an improved awareness in the medical community, progress in the accuracy of diagnostic procedures in pathology and radiological imaging, as well as recently developed classification systems. Around $25 \%$ of all NETs originate from the bronchopulmonary system. $20-25 \%$ of all malignant lung tumors are neuroendocrine neoplasms (NENs), if the poorly differentiated variants are included.

Following the World Health Organization (WHO) classification (tables 1 and 2), 80-90\% of all carcinoids of the lung can be classified as typical carcinoids (TCs), 10-20\% as atypical carcinoids (ACs). 5-15\% of the bronchopulmonary carcinoid tumors are associated with the multiple endocrine neoplasia type 1 (MEN-1) syndrome [7]. TCs are defined as welldifferentiated, slowly proliferating tumors with a generally good prognosis. ACs are defined as well-differentiated tumors with higher mitotic activity than TCs and/or the presence of necrosis. Concerning histopathology and prognosis, ACs are intermediate between TCs on the one hand and poorly differentiated neuroendocrine carcinomas (NECs), i.e. large-cell NEC (LCNEC) and small-cell lung carcinoma (SCLC), on the other hand. NECs are highly malignant and have a poor prognosis [5]. The proportion of ACs versus TCs is greater in men than in women [8]. In the series from Berlin-Buch, 86 patients with carcinoids of the lung had a median age of 63 years at initial diagnosis. Thus, carcinoids of the lung appear at the same age as lung NECs. However, carcinoids occur more often than NECs at a low disease stage. $6(7 \%)$ of the abovementioned 86 patients developed secondary tumors mostly localized in the lung. However, it remains difficult in these
Table 1. WHO 2004 classification of malignant lung tumors

\begin{tabular}{ll}
\hline Malignant lung tumor & Neuroendocrine tumor \\
\hline Squamous-cell carcinoma & \\
Small-cell carcinoma & \\
Adenocarcinoma & \\
Large-cell carcinoma & yes \\
Large-cell neuroendocrine carcinoma (LCNEC) & \\
Adenosquamous carcinoma & \\
Sarcoma-like carcinoma & yes \\
Carcinoid tumor & yes \\
$\quad$ Typical carcinoid (TC) & \\
Atypical carcinoid (AC) & \\
Salivary gland tumors & yes \\
Preinvasive lesions & \\
Diffuse idiopathic pulmonary neuroendocrine cell hyperplasia & \\
(DIPNECH) &
\end{tabular}

Table 2. Classification of lung NETs according to WHO 2004 [9]

\begin{tabular}{|c|c|c|c|}
\hline Tumor type & Mitotic count ${ }^{\mathrm{a}}$ & Necrosis & Cell size \\
\hline Typical carcinoid & $<2$ & absence & - \\
\hline Atypical carcinoid & $2-10$ & absence or punctiform & - \\
\hline Large-cell, poorly differentiated & $>10$ & large & larger \\
\hline Small-cell, poorly differentiated & $>10$ & large & $<3$ lymphocytes \\
\hline
\end{tabular}

${ }^{\text {a}}$ Per high-power field $\left(2 \mathrm{~mm}^{2}\right)$. 
Fig. 1. (a-c) Carcinoids visualized via bronchoscopy. Narrow band imaging was used in (b). Pictures provided by K. Darwiche, Essen.
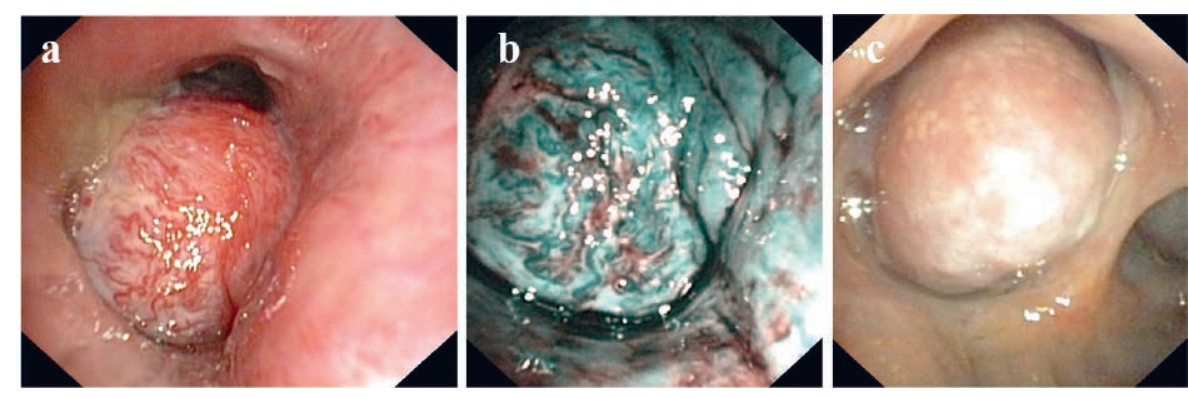

cases to distinguish between metastases or a secondary primary tumor.

Another rare entity with high differentiation and a very low tendency of proliferation and metastasis are neuroendocrine tumorlets. They are characterized as multifocally distributed TC tumors with a diameter of $\leq 5 \mathrm{~mm}$. This disease is denoted as diffuse idiopathic pulmonary neuroendocrine cell hyperplasia (DIPNECH) by the WHO classification. DIPNECH is a preneoplastic condition characterized by a generalized proliferation of pulmonary neuroendocrine cells $[4,9]$.

In contrast to the digestive tract, poorly differentiated NECs predominate in the lung. For example, SCLCs account for $15-20 \%$ and LCNECs for $3 \%$ of all lung tumors. Highly to moderately differentiated bronchopulmonary NETs (syn. carcinoids) are rare and comprise approximately $2 \%$ of all lung tumors [7]. In a series of the Cancer Center Erfurt comprising tissue samples of 1,385 resected lung cancer patients, $70(5 \%)$ tumors were identified as NENs, namely $42(3 \%)$ as carcinoids, $24(1.7 \%)$ as LCNECs, and $4(0.3 \%)$ as SCLCs with neuroendocrine characteristics [10]. The relatively small proportion of SCLCs in this series of resected tissue samples from lung cancer patients, which does not correspond to the actual prevalence of this tumor type, can be explained by the fact that most SCLC patients cannot be treated by surgical resection of the tumor.

A Norwegian registry including 26,665 lung cancers revealed a proportion of $1 \%$ carcinoids [11], and the German Registry of the Cancer Center Berlin-Buch found a proportion of $1.3 \%$ carcinoids in more than 6,000 lung cancers [8]. However, data from registries should be interpreted cautiously since there are a variety of limitations, due to diverging classification systems and potential allocation bias.

More than $60 \%$ of all patients with lung carcinoids are female. The 5-year survival rate in bronchopulmonary carcinoids is estimated at $90 \%$, in nodal stage N0 at $100 \%$ [12]. According to a survival analysis of 200 patients with bronchopulmonary NENs, the 5- and 10-year survival rates are $87 \%$ and $87 \%$ for TCs, $56 \%$ and $35 \%$ for ACs, $27 \%$ and $9 \%$ for LCNECs, and $9 \%$ and $5 \%$ for SCLCs, respectively [13]. In the Berlin-Buch series, the 5-year survival rate was $88 \%$ for TCs and $71 \%$ for ACs [8].

Due to the high proportion of low malignant tumor types with a relatively low mortality and long disease duration, the prevalence of lung NETs is considerable and can be estimated at approximately 5,000 patients in Germany. Nevertheless, in comparison with gastroenteropancreatic (GEP) NETs, much less data is available to define standards in diagnosis-guided and stage-adjusted therapy of lung NETs. The diagnostic and therapeutic management of NET patients essentially requires an interdisciplinary approach including experts of pathology, endocrinology, medical oncology, pulmonology, surgery, radiology, and nuclear medicine.

\section{Clinical Features, Bronchoscopic Exploration, and Biopsy}

Of all bronchopulmonary carcinoids, $20-30 \%$ are localized in the periphery of the lung and therefore are mostly asymptomatic. If the tumor is located in the central airways, the symptom triad of cough, hemoptysis, and frequent infections may be typical of early diagnosis. Only $2 \%$ of all patients with lung NETs present with the full carcinoid syndrome [7], which is caused by an excessive serotonin production and secretion by the tumor cells. In contrast to GEP NETs, it is not limited to patients with metastatic disease, because serotonin can enter the systemic circulation directly via bronchial arteries and pulmonal veins.

The parameter with the highest impact on NET behavior and prognosis is the histological classification of the tumor. Therefore, it is crucial to perform a highly qualified pathohistological analysis and diagnosis of the tumor. This can only be based on a specimen containing enough tumor cells and therefore requires at least a needle aspiration biopsy via bronchoscopy in all cases not eligible for tumor resection according to bronchoscopical and radiological findings. Beyond exploration of the primary tumor, endobronchial ultrasound with real-time guided transbronchial needle aspiration (EBUS-TBNA) allows the reliable diagnosis of mediastinal lymph nodes. As an important method of tumor staging, this method may replace mediastinoscopy.

The macroscopical features of TCs and ACs are very characteristic, so that a tentative diagnosis can be already drawn from bronchoscopical inspection. Carcinoids appear as smooth, well-demarcated, grey to yellow lumps (fig. 1). Due to their high vascularization, severe bleeding can be induced easily during biopsy. This can be avoided by the use of adequate 
prevention measures. Rigid bronchoscopy upon intubation anesthesia enables a better control of bleeding complications as compared to flexible bronchoscopy and permits obtaining big specimens for histological evaluation, either by rigid forceps or cryobiopsy. Therefore, rigid bronchoscopy should be preferred as soon as a NET is suspected.

In contrast to needle aspiration biopsy, exfoliative, abrasive, or imprinting techniques of cell sampling are insufficient for an accurate pathohistological differentiation. In addition, it is indispensable for the clinician to supply the pathologist with a complementing report including patient characteristics, clinical signs and symptoms, tumor localization and dissemination.

\section{Pathohistological Diagnosis}

Accordance between the different NEN classification systems of the WHO, the European Neuroendocrine Tumor Society (ENETS), the North American Neuroendocrine Tumor Society (NANETS), and the Union for International Cancer Control (UICC) has been increasing [1-5, 9, 14]. Standard parameters for the histological differentiation between TCs and ACs are the mitotic count and/or the presence of necrosis. TCs are characterized by less than 2 mitoses per $2 \mathrm{~mm}^{2}$ and the absence of necrosis. Accordingly, carcinoids presenting with 2-10 mitoses per $2 \mathrm{~mm}^{2}$ or foci of necrosis are classified as ACs [13]. Although not included in the WHO classification, Ki-67 can also be useful, at least as an ancillary parameter, for the differentiation between TCs and ACs. However, until now there is no consensus regarding the Ki-67 cutoff value in order to distinguish TCs from ACs. Mitosis rates and Ki-67 values differ to a greater extent in lung NETs than in GEP NETs. Therefore, it might be helpful to combine both parameters, particularly when the histopathological diagnosis remains undefined.

In squamous-cell carcinomas or adenocarcinomas, partial neuroendocrine differentiation can often be detected; however, this observation seems to be without any impact on prognosis or, according to current knowledge, on the response to therapy. These tumors are collectively referred to as NSCLCs with partial neuroendocrine differentiation. Nevertheless, the histopathological distinction between non-NEC, such as adenocarcinoma, and NEC is crucial in order to understand the biological background of the tumor. Generally, this discrimination cannot be based on the morphology of the tumor cells alone. Hence, for the detection of neuroendocrine components, immunohistochemical markers are an essential tool. NSCLC with suggestive neuroendocrine morphology, for example, should be assessed with neuroendocrine markers such as CD56, chromogranin A (CgA), and synaptophysin, which can be indicative of an LCNEC [15]. Virtually all TCs and ACs are positive for $\mathrm{CgA}$ and/or synaptophysin by immunohistochemistry. Neuron-specific enolase (NSE), the clinically relevant serum marker for poorly differentiated carcinomas (SCLC and LCLC), is not recommended for routine pathology, due to its low specificity.

Several other neuropeptides and amines are also frequently found in lung neuroendocrine neoplasms: bombesin, calcitonin, adrenocorticotropic hormone (ACTH), Leuenkephalin, gastrin, somatostatin, vasoactive intestinal polypeptide (VIP), neurotensin, arginine vasopressin, and serotonin. They may be helpful in identifying the neuroendocrine nature of a bronchopulmonary tumor; however, their routine pathological examination is not obligatory.

In a functionally active NET, the tumor excessively secretes one of a number of peptides or amines, such as 5-hydroxytryptophane, eventually causing specific clinical symptoms, such as the carcinoid syndrome due to the excessive secretion of serotonin (see above) or Cushing's syndrome due to the excessive secretion of ACTH.

Transcription factors can be helpful as immunohistochemical markers to differentiate between lung primaries and lung metastases from other tumor entities. For example, thyroid transcription factor-1 (TTF-1) is a highly specific indicator of a lung primary and, analogically, caudal-related homeobox-2 (CDX-2)-positive tumors have a high probability to stem from the digestive tract.

\section{Circulating Tumor Markers}

Measurements of serum or plasma tumor markers can be a valuable complementary tool for the follow-up of NET diagnostics. However, the levels of circulating biomarkers can fluctuate significantly and, in addition, neuroendocrine markers can also occur in a variety of non-NET entities. Therefore, the primary diagnosis of a NET can never be based on only these markers without taking into account other diagnostic parameters. In functionally active NETs, the respective peptides or amines produced by the tumor can generally be used as diagnostic markers.

Whereas CgA and NSE can be used as valuable tools for follow-up examination, they are not suitable for tumor screening. A third marker frequently used in NET diagnostics is 5-hydroxyindoleacetic acid (5-HIAA) measured in urine collected for $24 \mathrm{~h}$. As a surrogate parameter of serotonin metabolism, elevated 5-HIAA levels are indicative of a carcinoid syndrome (see above). Accordingly, 5-HIAA is frequently increased in patients with midgut NETs, but rarely in patients with lung NETs. 5-HIAA has a high specificity; however, many different foods and medications can alter the urinary 5-HIAA levels and may thereby generate false-positive results $[16,17]$. A further limitation to the sensitivity of 5-HIAA measurements in lung NETs is given by the fact that 5-hydroxytryptophane decarboxylase expression is diminished in many of these tumors, resulting in reduced production of 5-HIAA. 


\section{Imaging}

In the last decades, imaging technology has remarkably improved and a number of new diagnostic tools have been developed, in NETs and in other tumor entities. In parallel, there is a significant increase in image resolution and an improvement of specific contrast techniques. Requirements for radiological diagnostics of lung NENs are generally based on the same principles as in non-neuroendocrine lung tumors. The most important techniques in conventional imaging are computed tomography (CT) and magnetic resonance imaging (MRI). However, there are some significant advantages of using multislice CT in lung diagnostics, such as fast image acquisition to avoid movement artifacts and higher spatial resolution facilitating multiplanar reconstruction. For the diagnostics of lung NETs, an at least 16-slice CT is strongly recommended, whereas new scanners are usually equipped for more rapid image acquisition at submillimeter slice thickness by 64-row detectors and higher. In imaging with intravenous contrast media, it should be taken into account that, in general, the vascularization of NETs is extraordinarily high. In many cases, tumors can be seen clearly demarcated against solid tissues only in a very early (arterial) phase of contrast imaging, and therefore fast image acquisition is crucial.

According to the European Society for Medical Oncology (ESMO) guidelines, after primary surgery of a TC or AC, the patient should be followed up by CT or MRI once a year. Patients with metastatic or recurrent disease should be followed up more often during treatment with cytotoxic or biological agents, at 3-month intervals [7].

Another area of great progress during the last decade is functional imaging of NETs with the help of molecularly targeted agents. Labeling of somatostatin analogues (SSAs)
Fig. 2. ${ }^{68} \mathrm{Ga}$-DOTANOC PET/CT images from a 69-year-old patient with an NEC of the right middle lobe of the lung (stage IV) and hepatic and mediastinal metastases. Initially, a platinum-based chemotherapy was performed, followed by treatments with interferon, lantreotide, octreotide, and finally by chemotherapy with STZ and doxorubicin. The NEC disease progressed during all of these treatments. The ${ }^{68} \mathrm{Ga}$-DOTANOC PET/CT shows a primary tumor, which is located in segment 6 of the right lung and highly positive for SMS-R (standardized uptake value (SUV) 18.1) and extended bilobular metastases. (a) PET maximum intensity projection, (b) PET/CT coronal section, (c) CT axial section, (d) PET/CT axial section. Due to the high SMS-R density of the metastases, PRRT was indicated and performed with very good results, i.e. PR and long survival of the patient were achieved. Pictures provided by R. P. Baum, Bad-Berka.
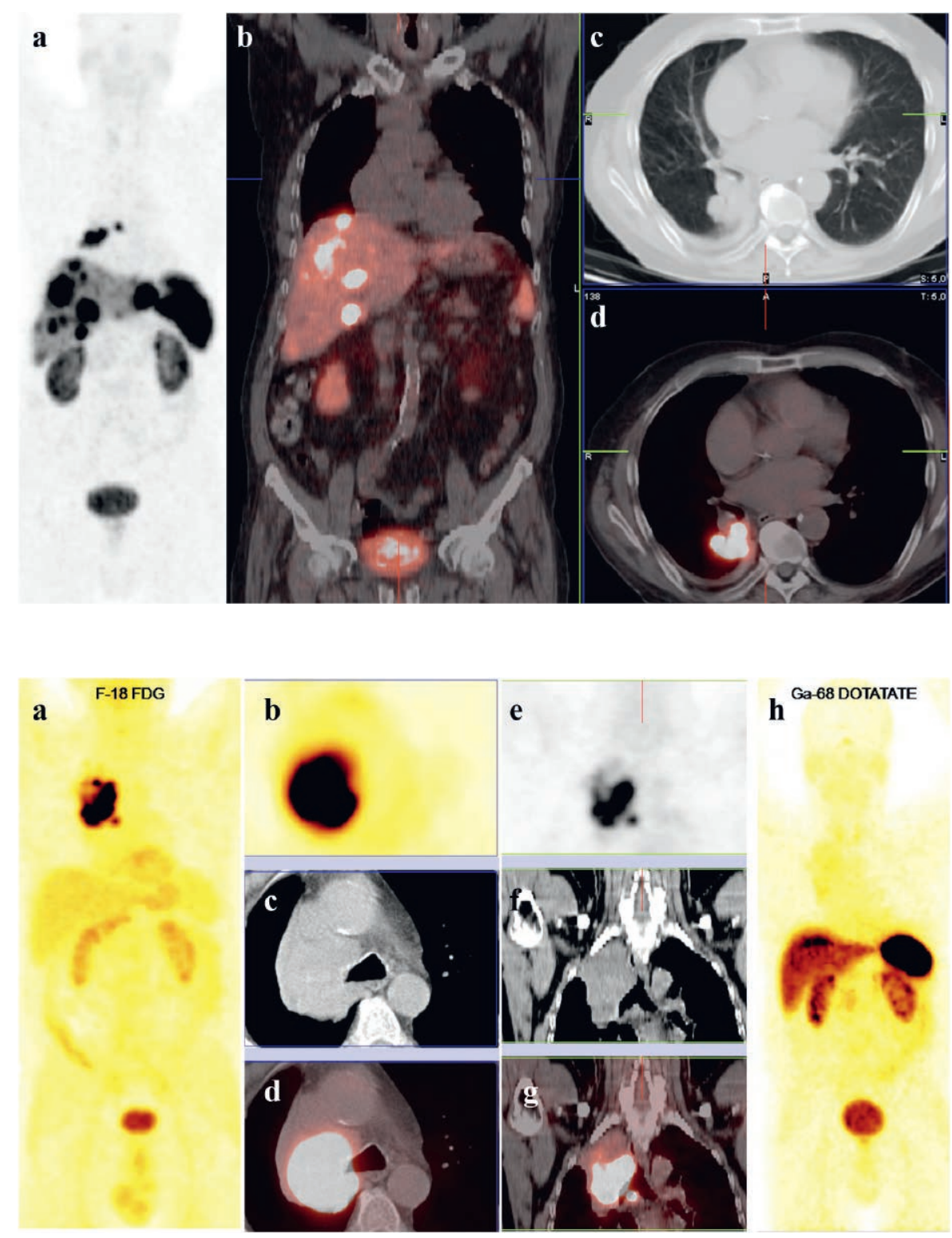

Ga-68 DOTATATE

h

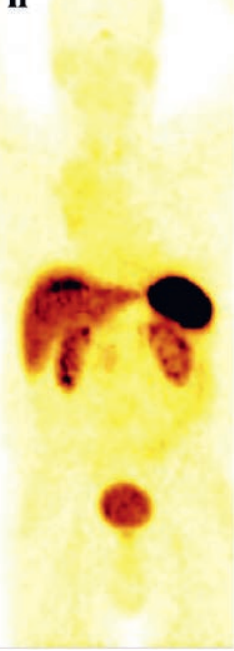

Fig. 3. In a 56-year-old female patient with $\mathrm{AC}$ in the right lobe of the lung, ${ }^{18} \mathrm{~F}-\mathrm{FDG}$ PET/CT images show intensive glucose hypermetabolism (SUV 16.7) of the 7.5-cm-large tumor which is obstructing the upper bronchial lobe. (a) Maximum intensity projection, (b) PET axial section, (c) CT axial section, (d) PET/CT axial section, (e-g) coronal sections. The locations of FDG-positive lymph node metastases are right-sided postclavicular, parathyroideal, and infracranial. ${ }^{68} \mathrm{Ga}$-DOTATATE PET/CT (h, maximum intensity projection) revealed no significant SMS-R expression. Therefore, PRRT was not recommended. Pictures provided by R. P. Baum, Bad-Berka. 
with radioisotopes such as the positron-emitting ${ }^{68}$ gallium allows the detection of NET primaries and metastases by positron emission tomography (PET)/CT, frequently even if they are too small to be detected with conventional imaging methods, such as tumors located in the bronchus. PET/CT has the highest specificity and sensitivity among the functional imaging techniques, followed by single photon emission computed tomography (SPECT)/CT and SPECT and planar somatostatin receptor scintigraphy (SRS) [18]. SRS with ${ }^{111}$ indium has no sufficient sensitivity with regard to the detection of lung NETs. Instead, ${ }^{99 \mathrm{~m}} \mathrm{Tc}$ SRS is recommended and SRS should always be combined with SPECT.

Beyond highly sensitive tumor detection, functional imaging allows reliable judgment on the somatostatin receptor (SMS-R) status of the tumor, including an estimation of the receptor density, providing important information concerning the suitability of SSAs and peptide receptor radionuclide therapy (PRRT) in the respective patient (figs. 2-4). Immunohistochemical evaluation of the SMS-R subtype 2A (SSTR2A) may be helpful as an additive tool, especially in case of initial diagnosis of a bronchopulmonary NET. An open question is whether in TCs, based on the Response Evaluation Criteria in Solid Tumors (RECIST) and the Positron Emission Tomography Response Criteria in Solid Tumors (PERCIST), an SMS-R
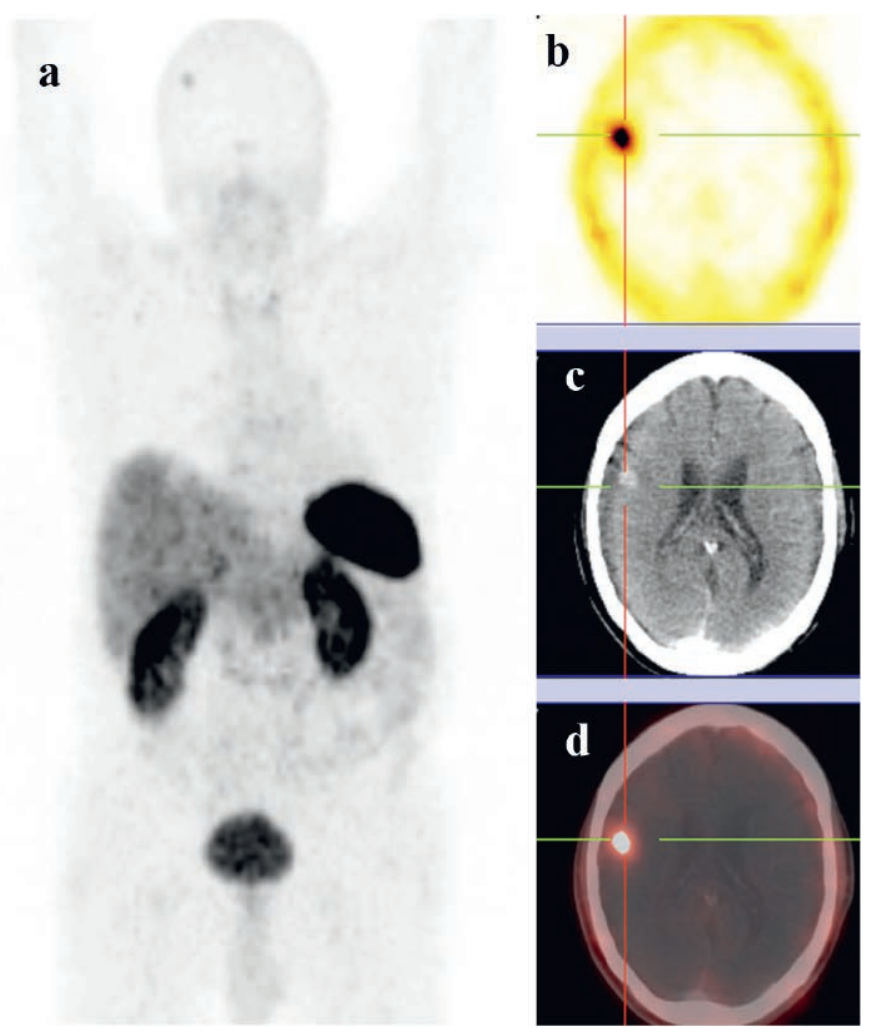

Fig. 4. ${ }^{68} \mathrm{Ga}$-DOTATOC PET/CT of a 72-year-old patient with lung NEC. The images show only minimal SMS-R expression in the primary tumor, which is located in the right lung. Additionally, a cerebral metastasis was detected, supporting the indication for percutaneous radiation therapy. (a) Maximum intensity projection, (b) PET axial section, (c) CT axial section, (d) PET/CT axial section. Pictures provided by R. P. Baum, Bad-Berka.
PET/CT should be generally performed for continuous follow-up diagnostics. An alternative proposal is to use conventional imaging for regular follow-up and, as recommended for GEP NETs, to perform a PET/CT every 18-24 months.

TCs tend to be SSTR positive whereas many ACs are better detectable by ${ }^{18} \mathrm{~F}$-fluorodeoxyglucose $\left({ }^{18} \mathrm{~F}\right.$-FDG) PET/ CT than by using other tracers. Hence, tracer selection should be based primarily on the histological classification including the proliferation rate of the tumor. If the Ki-67 index exceeds 10-20\%, an FDG-PET/CT is always suitable. In order to identify the peptide that is best fitting for SMS-R imaging in a particular patient, differentiation of SMS-R subtypes 1-5 (SSTR1-5) by immunohistochemistry might be considered; however, this method is so far not well established. Finally, the expression analysis of various subtypes of SMS-Rs in correlation with functional imaging has to be evaluated in further studies [19, 20].

\section{Surgical Therapy}

The only curative treatment of lung NETs is their complete resection. In the Erfurt series [10], the 5-year survival probability reached $80 \%$ in all patients after lung NET resection. Even in the subgroup of patients with disease stage IV, a prior R0 resection seemed to improve the survival probability compared to patients with lower incomplete resection types. However, these observations are preliminary due to methodological limitations. Anyway, based on a larger amount of data, it has been proven that NET patients after curative surgery have a much better prognosis than patients with carcinoma of the lung. In the above-mentioned analysis of the Norwegian registry [11], e.g., the 5-year survival rate was $96 \%$ after resection of TCs and $79 \%$ after resection of ACs.

In peripherally localized TCs without suspected node involvement, a parenchyma-sparing resection is indicated, such as an ample wedge excision or a segmental resection [21]. Bronchial carcinoids are treated by sleeve resection with lobectomy rather than pneumonectomy. In selected cases, isolated bronchial resections and bronchoplastic reconstructions without lung resection can be performed [22]. With regard to the high frequency of lymphatic involvement in ACs, in most cases this tumor type should be treated like bronchial carcinoma, by radical resection [23].

Centrally located TCs or ACs frequently may cause considerable airway occlusions and are therefore usually discovered at an early disease stage. Under certain circumstances, these tumors can be resected by the use of minimally invasive techniques. For tumors that are not considered to be surgically resectable, the use of local ablation methods such as cryoablation or laser ablation can be discussed on an individual basis. Interventional bronchoscopy can also be used to restore free passage of the respiratory tract. In some cases, this may facilitate a later curative surgical approach. 
It should be noted that, beyond the intraluminal part of the tumor which is visible in bronchoscopy, there is sometimes a much bigger extraluminal tumor mass which can be detected using EBUS. The minimally invasive approach is recommended only for patients who are unfit for surgery. In these cases, photodynamic therapy might be a good option [24]. Endoscopic resection should be followed up by control endoscopies at frequent intervals.

In patients with neuroendocrine tumorlets (DIPNECH), 1 or 2 of the lesions should be resected via thoracoscopy in order to prove the diagnosis histologically. All lesions should be followed up at regular intervals. Since this is rather a slowly growing tumor disease, 6-month intervals by conventional imaging seem to be appropriate. Tumor resections may be considered in the case of radiological progression of single lesions, unless a systemic treatment is required.

\section{Biotherapy}

The symptoms of hormonal excess in functionally active NETs of the lung can be similar to those in GEP NETs. Carcinoid syndrome (see above) can be treated effectively with SSAs such as octreotide or lanreotide. In cases of insufficient response to monotherapy, the SSAs may be combined with interferon alpha.

Due to only sparse data from clinical studies concerning the antitumor effects of SSAs in lung NETs, it remains unclear whether there is a comparable antiproliferative effect to that shown for octreotide LAR in patients with advanced welldifferentiated midgut NETs [25]. The same holds true for other biotherapies such as interferon. The new SSA SOM230 (pasireotide) is an SSTR multiligand. Preliminary results from phase II clinical studies show its efficacy in patients with intestinal NETs and octreotide-refractory carcinoid syndrome [26].

\section{Peptide Receptor Radionuclide Therapy}

Radiolabeled SSAs are used in PRRT for the treatment of SSTR-positive NETs. Results from non-controlled, mostly monocentric clinical trials are encouraging. Using third-generation SSTR-based radiopharmaceuticals, namely ${ }^{177}{ }^{\text {Lu-DOTA }}{ }^{0}$-Tyr ${ }^{3}$-octreotate $\left({ }^{177}\right.$ Lu-DOTATATE; DOTA = 1,4,7,10-tetraazacyclododecane- $N, N$ ', $N$ ", $N$ "'-tetraacetic acid), the adverse effects of PRRT are mostly mild. Serious adverse effects like myelodysplastic syndrome/acute myelogenous leukemia or chronic renal failure are very rare. However, possible long-term effects on renal functions need to be taken into account when using ${ }^{90}$ Y-labeled peptides. According to a systematic review, with ${ }^{177} \mathrm{Lu}$-DOTATATE, tumor regression of $50 \%$ or more was demonstrated in $28 \%$ of NET patients and of $25-50 \%$ in $19 \%$ of all patients. Stable disease (SD) was achieved in $35 \%$, and in $18 \%$ of all patients the disease was progressing. The review included 9 (7\%) patients with lung carcinoids, 4 with TCs, and 5 with ACs. The median time to progression after PRRT with ${ }^{177}$ Lu-DOTATATE was 31 months in this small subgroup. In 5 patients partial remission (PR) was achieved, 1 patient demonstrated minor remission, and 2 patients had SD [27]. However, there is no data yet from randomized controlled studies and prospective evaluation of tumor response rates and survival. Furthermore, there are no trials restricted to patients with lung NETs, and only few subgroup analyses exist with small numbers of lung NET patients from previous studies.

\section{Chemotherapy}

Only sparse data exists also concerning the chemotherapy of NETs of the lung. Therefore, no standard treatment regimen has been established yet [28]. Streptozotocine (STZ)based regimens have no significant value in SCLC treatment [29]. Furthermore, in advanced NETs of the lung, the results of STZ-based therapies in terms of response and stabilization rates are rather discouraging and suggest that NETs of the lung include a high proportion of STZ-resistant tumors [30]. In a non-controlled trial, 36 patients with metastatic NETs were treated with a combination of cisplatin and etoposide (PE). In 18 of these patients, the tumor originated from the lung or from the thymus, of which 5 were atypical. In this subgroup of thoracic NETs, $56 \%$ responded to therapy with a medium duration of 9 months, one-third achieved SD [31]. These results have made the $\mathrm{PE}$ regimen a valuable comparator in this patient group. However, there is no consensus yet on the question of whether the use of cisplatin and etoposide should be limited to SCLC treatment or extended to other advanced NETs of the lung.

At least in patients with LCNEC, cisplatin-containing combinations have been shown to be of particular relevance [32]. In a retrospective series of 20 patients with LCNEC treated with different cisplatin-based regimens, 1 patient showed complete response (CR) and 9 showed PR, yielding an objective response rate of $50 \%$. These results suggest that the response rate of LCNECs to cisplatin-based chemotherapy is comparable to that of SCLCs [33] and they should be treated alike.

Temozolomide-based chemotherapies have been revealed to be effective in patients with pancreatic NETs and might serve as an alternative treatment option in lung NETs. A phase II study included 36 patients with advanced welldifferentiated NETs. 13 of them were bronchial NETs, i.e. 10 TCs and 3 ACs. All patients received oral temozolomide for 5 consecutive days within 28-day cycles after failure of several other treatments. $4(31 \%)$ patients achieved a PR, whereas 4 others (31\%) showed SD [34]. Other compounds in the chemotherapy of lung NETs include, e.g., capecitabine and/or oxaliplatin. 


\section{Molecularly Targeted Agents}

Several new compounds are candidates for molecularly targeted therapy in NETs. However, only few agents have been evaluated in controlled clinical trials, so far. Nonetheless there are results from 2 phase III clinical trials with the tyrosine kinase inhibitor sunitinib and the mammalian target of rapamycin (mTOR) inhibitor everolimus (RAD001). These trials exclusively included pancreatic NET patients. With both agents, an increase of the median progression-free survival (PFS) by 6 months compared to placebo could be demonstrated, whereas the objective response rates according to RECIST were low: 9\% for sunitinib and 5\% for everolimus. Generally, these compounds were well tolerated and adverse events declined in most cases within the first 3 months of treatment $[35,36]$.

Everolimus and sunitinib have been approved recently for the treatment of advanced well-differentiated NETs of pancreatic origin with tumor progression; there are, however, no data on the efficacy of sunitinib in lung NETs.

In the phase III trial RADIANT-2 (Aㅡㅇㅛ 001 In $\underline{\text { Advanced }}$ Neuroendocrine Tumors-2), everolimus was compared with placebo, both in combination with octreotide, including 429 patients with advanced, well- to intermediately differentiated NETs of different origin. Primary endpoint of the trial was the median PFS undergoing a centralized radiological review, which was 16.4 months with everolimus versus 11.3 months with placebo for the overall cohort of patients. According to that, everolimus was associated with a $23 \%$ reduction in risk of progression (hazard ratio (HR) 0.77 ; $95 \%$ confidence interval (CI) 0.59-1.00; $\mathrm{p}=0.026$ ), but the log rank test one-sided $\mathrm{p}$-value did not meet the pre-specified significance level of $\mathrm{p}=0.0246$. However, the median PFS by investigator review was 12.0 and 8.6 months for everolimus and placebo, respectively, and thus consistent with the central analysis. From this point of view, everolimus was associated with a clinically significant reduction in risk of progression by $22 \%$ (HR 0.78; 95\% CI 0.62-0.98; $p=0.018$ ) [37]. From this study, a subgroup of 44 patients with lung carcinoids was looked at in an exploratory PFS analysis. Although this is a small patient cohort, it is the largest number of patients with lung NETs prospectively evaluated in a clinical trial. $75 \%$ of these patients had received everolimus, $25 \%$ placebo. Within the lung carcinoid subgroup, the PFS analysis showed a nonsignificant trend in favor of everolimus versus placebo. The median PFS was 13.6 months in the everolimus subgroup and 5.6 months in the placebo subgroup [38]. Due to diverging characteristics of the two patient groups, these results must be interpreted with caution until they can be verified in further prospective clinical studies with larger numbers of patients. However, this could be an important step forward in the management of this tumor. The RADIANT-4 study (see below) will further evaluate the role of everolimus in lung (and GI) NETs compared to placebo.
Within the single-arm open-label study RAMSETE

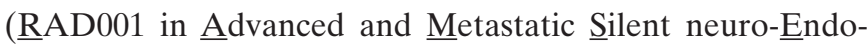
crine Tumors in Europe), patients received a monotherapy with everolimus. 73 Patients with non-functional, non-pancreatic NETs of different origins, including the lung, were recruited. $55(75 \%)$ of the patients discontinued, 23 due to disease progression, another 23 due to adverse events. According to the centralized review, $55 \%$ of the patients reached SD after prior disease progression and the median PFS was 185 days [39].

\section{Future Perspectives}

Currently, patients with advanced NETs of GI or lung origin and without a history of carcinoid syndrome are being recruited for the multicenter study RADIANT-4 (CRAD001T2302). In combination with best supportive care, everolimus will be compared to placebo in a randomized double-blind setting. The study is planned to enroll 279 patients from over 120 sites worldwide. Treatment-naive patients will be included as well as patients with disease progression on or after the last treatment [40].

The European multicenter 3-arm trial CSOM230DIC03 including everolimus will start to recruit patients with lung NETs. The trial will compare the effectiveness and tolerability of everolimus or the SSA SOM230 (see above), alone or in combination, in about 80 patients with advanced TCs and ACs of the lung and thymus [41]. Using the typical platinumdoublet backbone as a standard approach, the German study CRAD001KDE37 is currently investigating the effectiveness and tolerability of the combination of everolimus, paclitaxel, and carboplatin in approximately 85 patients with advanced LCNEC [42]. These two trials are coordinated for Germany by Wilfried Eberhardt (CSOM230DIC03) and Michael Thomas (CRAD001KDE37).

Another agent that might be of interest for the therapy of patients with lung NETs is the angiogenesis inhibitor bevacizumab. A phase II study compared bevacizumab to polyethylene glycol (PEG) interferon alpha-2b, both in combination with octreotide. The trial included 44 patients with advanced NETs of different origins, $4(2.3 \%)$ of them originating from the lung. Upon bevacizumab treatment, 4 patients $(18 \%)$ demonstrated a PR, 17 patients (77\%) SD, and 1 patient $(5 \%)$ PD. Upon treatment with PEG interferon, 15 patients $(68 \%)$ achieved SD and 6 patients (27\%) developed PD. The PFS rates after 18 weeks of monotherapy were $95 \%$ with bevacizumab versus $68 \%$ in the PEG interferon arm [43].

\section{Summary and Conclusions}

NETs of the bronchopulmonary system are a rare entitity of highly to moderately differentiated tumors, which can be 
classified by their histology, proliferative activity, TNM staging, endocrinological activity and hereditary background. Welldifferentiated bronchopulmonary NETs comprise approximately $2 \%$ of all lung tumors. Prognosis in TCs is mostly good. In ACs, histopathology and prognosis are intermediate between TCs on the one hand and LCNEC or SCLC on the other hand. The overall 5-year survival rate in bronchopulmonary carcinoids can be estimated at $90 \%$. A huge proportion of the bronchopulmonary carcinoids are asymptomatic at initial diagnosis. In other cases, they appear with cough, hemoptysis, and bronchopulmonary infections. Bronchoscopical exploration and adequate cell sampling through biopsy are crucial for the correct diagnosis of the tumor. For the pathohistological differentiation between TC and AC, the mitotic count and the presence of necrosis are the most important parameters. Immunohistochemistry can be useful for the diagnosis of NETs as well as for the detection of a neuroendocrine component, for example in squamous-cell carcinomas or adenocarcinomas Virtually all TCs and ACs are positive for CgA and synaptophysin. Contrarily, NSE, which is the commonly used marker for SCLC and LCLC, has a very low specificity and is therefore not suitable for routine pathology in NETs. Serum markers such as CgA and NSE can be valuable tools for follow-up examination, but not for tumor screening. Measurement of 5-HIAA is of limited value in most lung NETs. New imaging techniques, especially functional imaging with radiolabeled SSA, significantly improved the diagnosis of NETs.

The only curative treatment for lung NETs is their complete resection. The use of ablation methods should be considered in tumors that cannot be completely resected via surgery. Carcinoid syndrome can be treated effectively with SSAs. However, concerning NETs of the lung, it remains unclear whether there is an additional effect of biotherapy in terms of tumor control. Results from non-controlled trials with PRRT are promising and need further evaluation in randomized controlled studies. Due to sparse clinical data, there is so far no standard chemotherapy regimen for NENs of the lung. A high proportion of NETs seems to be STZ resistant. Promising candidates for chemotherapy components in the field of bronchopulmonary NETs are, e.g., cisplatin, etoposide, temozolomide, capecitabine, and oxaliplatin. The new molecularly targeted compounds everolimus and sunitinib have been recently approved for the treatment of advanced, progressing well-differentiated pancreatic NETs. First results with everolimus in the treatment of lung NETs are promising. However, they are based on studies with small numbers of lung NET patients, and further research in randomized controlled studies is necessary to draw reliable conclusions.

The introduction of new therapies in the treatment of NETs can be expected for the future. However, there is still a great need to generate meaningful clinical data for patients with lung NETs, which are even rarer than NETs in general. For this reason, the implementation of specific lung NET registries and cross-linking international research activities are critical for the future of this field. Since NETs of the lung and GEP NETs share some features with respect to biological behavior and clinical characteristics, it may be reasonable to establish common interdisciplinary tumor boards and registries as well. However, no consensus could be achieved concerning this question, and there may also be certain benefits in NET treatment associated with tumor boards specialized in thoracic oncology. Currently, LUNGEN NET, which is a German prospective registry for NETs of the bronchopulmonary system, is being implemented under the chairmanship of Christian Grohé and Dieter Hörsch.

\section{Acknowledgement}

This report was developed in close cooperation with a medical writer.

\section{Disclosure Statement}

D.H. received honoraria, payments of travel expenses, and research funds from the firms Novartis, Ipsen, Pfizer, Eckart und Ziegler, ITG, Covidien, and MDS Nordion. T.D. received honoraria for presentations and travel expenses for attending scientific conferences from the firms Bayer Schering Pharma and Novartis. C.S. works as an advisory board member for Novartis and Pfizer, and received research grants from Novartis and honoraria for presentations from the firms Novartis and Ipsen. For his presentation on the expert meeting in Weimar, C.G. received an honorarium. For his presentation on the expert meeting in Weimar, D.F.H. received an honorarium and reimbursement of his travel expenses. M.S. received honoraria for presentations from the firms Roche, Lilly, Boehringer, and Novartis. M.P. received honoraria for her work in advisory boards and for presentations from the firms Novartis, Ipsen, and Pfizer. M.M.W. received research funding, speaker and consultant honoraria from the firms Novartis, Pfizer, and Ipsen. For his presentation on the expert meeting in Weimar, H.H received an honorarium. K.W.S., M.A., K.D., R.P.B., N.P., C.S., T.K., C.F.W., K.-M.D., R.A., and R.M.H. declare that they have no conflicts of interest concerning the submitted work.

\section{References}

$\checkmark 1$ Klöppel G, Couvelard A, Perren A, Komminoth P, McNicol AM, Nilsson O, Scarpa A, Scoazec JY, Wiedenmann B, Papotti M, Rindi G, Plöckinger U; Mallorca Consensus Conference participants; European Neuroendocrine Tumor Society: ENETS Consensus Guidelines for the Standards of Care in Neuroendocrine Tumors: towards a standardized approach to the diagnosis of gastroenteropancre- atic neuroendocrine tumors and their prognostic stratification. Neuroendocrinology 2009;90:162166.

2 Sobin LH, Gospodarowicz MK, Wittekind C:TNM Classification of Malignant Tumours, ed 7. Chichester, Wiley-Blackwell, 2009.

3 Rindi G: The ENETS guidelines: the new TNM classification system. Tumori 2010;96:806-809.
4 Rindi G, Arnold R, Bosman FT, Capella C, Klimstra DS, Klöppel G, Komminoth P, Solcia E: Nomenclature and classification of neuroendocrine neoplasms of the digestive system; in Bosman FT, Carniero F, Hruban RH, Theise ND (eds): WHO Classification of Tumours of the Digestive System, ed 4. Lyon, IARC, 2010, pp 13-14. 
55 Anlauf M: Neuroendocrine neoplasms of the gastroenteropancreatic system: pathology and classification. Horm Metab Res 2011;43:825-831.

6 Yao JC, Hassan M, Phan A, Dagohoy C, Leary C, Mares JE, Abdalla EK, Fleming JB, Vauthey JN, Rashid A, Evans DB: One hundred years after 'carcinoid': epidemiology of and prognostic factors for neuroendocrine tumors in 35,825 cases in the United States. J Clin Oncol 2008;26:3063-3072.

7 Öberg K, Hellman P, Kwekkeboom D, Jelic S ESMO Guidelines Working Group: Neuroendocrine bronchial and thymic tumours: ESMO clinical practice guidelines for diagnosis, treatment and follow-up. Ann Oncol 2010;21(suppl 5):v220-v222.

8 Grohe C, data on file.

9 Gosney J, Travis WD: Pathology and genetics: tumors of the lung, pleura, thymus and heart in Travis W, Brambilla E, Müller-Hermelink H, Harris C (eds): World Health Organization classification of tumors. Lyon, IARC, 2004, pp 76-77.

10 Presselt N, data on file.

11 Naalsund A, Rostad H, Strøm EH, Lund MB Strand TE: Carcinoid lung tumors - incidence, treatment and outcomes: a population-based study. Eur J Cardiothorac Surg 2011;39:565-569.

12 Cardillo G, Sera F, Di Martino M, Graziano P, Giunti R, Carbone L, Facciolo F, Martelli M: Bronchial carcinoid tumors: nodal status and longterm survival after resection. Ann Thorac Surg 2004;77:1781-1785.

13 Travis WD, Rush W, Flieder DB, Falk R, Fleming MV, Gal AA, Koss MN: Survival analysis of 200 pulmonary neuroendocrine tumors with clarification of criteria for atypical carcinoid and its separation from typical carcinoid. Am J Surg Pathol 1998;22:934-944.

-14 Phan AT, Oberg K, Choi J, Harrison LH Jr, Hassan MM, Strosberg JR, Krenning EP, Kocha W, Woltering EA, Maples WJ; North American Neuroendocrine Tumor Society (NANETS): NANETS consensus guideline for the diagnosis and management of neuroendocrine tumors: well-differentiated neuroendocrine tumors of the thorax (includes lung and thymus). Pancreas 2010;39:784798.

15 Travis WD, Brambilla E, Noguchi M, Nicholson AG, Geisinger KR, Yatabe Y, Beer DG, Powell CA Riely GJ, Van Schil PE, Garg K, Austin JH, Asamura H, Rusch VW, Hirsch FR, Scagliotti G, Mitsudomi T, Huber RM, Ishikawa Y, Jett J, Sanchez-Cespedes M, Sculier JP, Takahashi T, Tsuboi M, Vansteenkiste J, Wistuba I, Yang PC, Aberle D, Brambilla C, Flieder D, Franklin W, Gazdar A, Gould M, Hasleton P, Henderson D, Johnson B, Johnson D, Kerr K, Kuriyama K, Lee JS, Miller VA, Petersen I, Roggli V, Rosell R, Saijo N, Thunnissen E, Tsao M, Yankelewitz D: International Association for the Study of Lung Cancer/American Thoracic Society/European Respiratory Society international multidisciplinary classification of lung adenocarcinoma. J Thorac Oncol 2011;6:244-248.

16 Vinik AI, Woltering EA, Warner RR, Caplin M, O'Dorisio TM, Wiseman GA, Coppola D, Go VL; North American Neuroendocrine Tumor Society (NANETS): NANETS consensus guidelines for the diagnosis of neuroendocrine tumor. Pancreas 2010;39:713-734.

- 17 Öberg K, Astrup L, Eriksson B, Falkmer SE, Falkmer UG, Gustafsen J, Haglund C, Knigge U, Vatn MH, Välimäki M; Nordic NE Tumour Group: Guidelines for the management of gastroenteropancreatic neuroendocrine tumours (including bronchopulmonary and thymic neoplasms). Acta Oncol 2004;617-636.

18 Baum RP, Prasad V, Hommann M, Hörsch D: Receptor PET/CT imaging of neuroendocrine tumors. Recent Results Cancer Res 2008;170:225242.

19 Kaemmerer D, Khatib-Chahidi K, Baum RP, Hörsch D, Presselt N, Sänger J, Kunze A, Hommann M: Concomitant lung and gastroenteropancreatic neuroendocrine tumors and the value of gallium-68 PET/CT. Cancer Imaging 2011;11: 179-183.

20 Baum RP, Kulkarni HR, Carreras C: Peptides and receptors in image-guided therapy: theranostics for neuroendocrine neoplasms. Semin Nucl Med 2012;42:190-207.

21 Yendamuri S, Gold D, Jayaprakash V, Dexter E, Nwogu C, Demmy T: Is sublobar resection sufficient for carcinoid tumors? Ann Thorac Surg 2011;92:1774-1778.

22 Machuca TN, Cardoso PF, Camargo SM, Signori L, Andrade CF, Moreira AL, Moreira Jda S, Felicetti JC, Camargo JJ: Surgical treatment of bronchial carcinoid tumors: a single-center experience. Lung Cancer 2010;70:158-162.

23 Stamatis G, Freitag L, Greschuchna D: Limited and radical resection for tracheal and bronchopulmonary carcinoid tumour. Report on 227 cases. Eur J Cardiothorac Surg 1990;4:527-532.

24 Van Boxem TJ, Venmans BJ, van Mourik JC, Postmus PE, Sutedja TG: Bronchoscopic treatment of intraluminal typical carcinoid: a pilot study. J Thorac Cardiovasc Surg 1998;116:402-406.

25 Rinke A, Müller HH, Schade-Brittinger C, Klose KJ, Barth P, Wied M, Mayer C, Aminossadati B, Pape UF, Bläker M, Harder J, Arnold C, Gress T, Arnold R; PROMID Study Group: Placebo-controlled, double-blind, prospective, randomized study on the effect of octreotide LAR in the control of tumor growth in patients with metastatic neuroendocrine midgut tumors: a report from the PROMID Study Group. J Clin Oncol 2009;27: 4656-4663.

26 Kvols LK, Oberg KE, O’Dorisio TM, Mohideen P, de Herder WW, Arnold R, Hu K, Zhang Y, Hughes G, Anthony L, Wiedenmann B: Pasireotide (SOM230) shows efficacy and tolerability in the treatment of patients with advanced neuroendocrine tumors refractory or resistant to octreotide LAR: results from a phase II study. Endocr Relat Cancer 2012;19:657-666.

27 Van Essen M, Krenning EP, De Jong M, Valkema R, Kwekkeboom DJ: Peptide receptor radionuclide therapy with radiolabelled somatostatin analogues in patients with somatostatin receptor positive tumours. Acta Oncol 2007;46:723-734.

28 Kvols LK, Brendtro KL; North American Neuroendocrine Tumor Society (NANETS): The North American Neuroendocrine Tumor Society (NANETS) guidelines: mission, goals, and process. Pancreas 2010;39:705-706.

29 Goeckenjan G, Sitter H, Thomas M, Branscheid D, Flentje M, Griesinger F, Niederle N, Stuschke M, Blum T, Deppermann KM, Ficker JH, Freitag L, Lübbe AS, Reinhold T, Späth-Schwalbe E, Ukena D, Wickert M, Wolf M, Andreas S, Auberger T, Baum RP, Baysal B, Beuth J, Bickeböller H, Böcking A, Bohle RM, Brüske I, Burghuber O, Dickgreber N, Diederich S, Dienemann H, Eberhardt W, Eggeling S, Fink T, Fischer B, Franke M, Friedel G, Gauler T, Gütz S, Hautmann H, Hellmann A, Hellwig D, Herth F, Heussel CP, Hilbe W, Hoffmeyer F, Horneber M,
Huber RM, Hübner J, Kauczor HU, Kirchbacher K, Kirsten D, Kraus T, Lang SM, Martens U, MohnStaudner A, Müller KM, Müller-Nordhorn J, Nowak D, Ochmann U, Passlick B, Petersen I, Pirker R, Pokrajac B, Reck M, Riha S, Rübe C, Schmittel A, Schönfeld N, Schütte W, Serke M, Stamatis G, Steingräber M, Steins M, Stoelben E, Swoboda L, Teschler H, Tessen HW, Weber M, Werner A, Wichmann HE, Irlinger Wimmer E, Witt C, Worth H; German Respiratory Society; German Cancer Society: Prevention, diagnosis, therapy, and follow-up of lung cancer: interdisciplinary guideline of the German Respiratory Society and the German Cancer Society. Pneumologie 2011;65:39-59.

30 Granberg D, Eriksson B, Wilander E, Grimfjärd P, Fjällskog ML, Oberg K, Skogseid B: Experience in treatment of metastatic pulmonary carcinoid tumors. Ann Oncol 2001;12:1383-1391.

31 Fjällskog ML, Granberg DP, Welin SL, Eriksson C, Oberg KE, Janson ET, Eriksson BK: Treatment with cisplatin and etoposide in patients with neuroendocrine tumors. Cancer 2001;92:11011107.

32 Modlin IM, Pavel M, Kidd M, Gustafsson BI: Review article: somatostatin analogues in the treatment of gastroenteropancreatic neuroendocrine (carcinoid) tumours. Aliment Pharmacol Ther 2010;31:169-188.

33 Yamazaki S, Sekine I, Matsuno Y, Takei H, Yamamoto N, Kunitoh H, Ohe Y, Tamura T, Kodama T, Asamura H, Tsuchiya R, Saijo N: Clinical responses of large cell neuroendocrine carcinoma of the lung to cisplatin-based chemotherapy. Lung Cancer 2005;49:217-223.

34 Ekeblad S, Sundin A, Janson ET, Welin S, Granberg D, Kindmark H, Dunder K, Kozlovacki G, Orlefors H, Sigurd M, Oberg K, Eriksson B, Skogseid B: Temozolomide as monotherapy is effective in treatment of advanced malignant neuroendocrine tumors. Clin Cancer Res 2007;13: 2986-2991.

35 Raymond E, Dahan L, Raoul JL, Bang YJ, Borbath I, Lombard-Bohas C, Valle J, Metrakos P, Smith D, Vinik A, Chen JS, Hörsch D, Hammel P, Wiedenmann B, Van Cutsem E, Patyna S, Lu DR, Blanckmeister C, Chao R, Ruszniewski P: Sunitinib malate for the treatment of pancreatic neuroendocrine tumors. N Engl J Med 2011;364: 501-513.

36 Yao JC, Shah MH, Ito T, Bohas CL, Wolin EM, Van Cutsem E, Hobday TJ, Okusaka T, Capdevila J, de Vries EG, Tomassetti P, Pavel ME, Hoosen S, Haas T, Lincy J, Lebwohl D, Öberg K; RAD001 in Advanced Neuroendocrine Tumors, Third Trial (RADIANT-3) Study Group: Everolimus for advanced pancreatic neuroendocrine tumors. N Engl J Med 2011;364:514-523.

37 Pavel ME, Hainsworth JD, Baudin E, Peeters M, Hörsch D, Winkler RE, Klimovsky J, Lebwohl D, Jehl V, Wolin EM, Oberg K, Van Cutsem E, Yao JC; RADIANT-2 Study Group: Everolimus plus octreotide long-acting repeatable for the treatment of advanced neuroendocrine tumours associated with carcinoid syndrome (RADIANT-2): a randomised, placebo-controlled, phase 3 study. Lancet 2011;378:2005-2012.

38 Fazio N, Granberg D, Grossman A, Saletan S, Klimovsky J, Panneerselvam A, Wolin EM: Everolimus plus octreotide LAR in patients with advanced lung neuroendocrine tumors: analysis of the phase III, randomized, placebo-controlled RADIANT-2 study. Chest 2013;143:955-962. 
39 Pavel ME, Wiedenmann B, Capdevila J, Reed N, Valle JW, Caglio S, May C, Comis S, Castellana R, de Herder WW, Metzner C, Salazar R, Hörsch D, Oberg K: RAMSETE: a single-arm, multicenter, single-stage phase II trial of RAD001 (everolimus) in advanced and metastatic silent neuro-endocrine tumours in Europe. J Clin Oncol 2012;30(suppl): abstr 4122 .

40 ClinicalTrials.gov: Everolimus plus best supportive care vs placebo plus best supportive care in the treatment of patients with advanced neuroendocrine tumors (GI or lung origin) (RADIANT-4) ClinicalTrials.gov Identifier: NCT01524783; other Study ID Numbers: CRAD001T2302,
2011-002887-26; last updated January 30, 2014. www.clinicaltrials.gov/ct2/show/NCT01524783 (last accessed February 12, 2014).

41 ClinicalTrials.gov: 3-Arm trial to evaluate pasireotide LAR/everolimus alone/in combination in patients with lung/thymus NET - LUNA Trial. ClinicalTrials.gov Identifier: NCT01563354; other Study ID Numbers: CSOM230DIC03, 2011-002872-17; last updated February 3, 2014. www.clinicaltrials.gov/show/NCT01563354 (last accessed February 12, 2014).

42 ClinicalTrials.gov: RAD001 with paclitaxel and carboplatin in first line treatment of patients with advanced large cell lung cancer with neuroendo- crine differentiation (MACS1419). ClinicalTrials. gov Identifier: NCT01317615; other Study ID Numbers: CRAD001KDE37, EudraCT 2010022273-34, 2010-022273-34; last updated December 15, 2013. www.clinicaltrials.gov/ct2/show/ NCT01317615 (last accessed February 12, 2014).

43 Yao JC, Phan A, Hoff PM, Chen HX, Charnsangavej C, Yeung SC, Hess K, Ng C, Abbruzzese JL, Ajani JA: Targeting vascular endothelial growth factor in advanced carcinoid tumor: a random assignment phase II study of depot octreotide with bevacizumab and pegylated interferon alpha- $2 \mathrm{~b}$. J Clin Oncol 2008;26:1316-1323. 